\title{
Transradial percutaneous coronary intervention for unprotected left main closure during acute myocardial infarction
}

\author{
Michał Chyrchel, Artur Dziewierz, Bernadeta Chyrchel, Dariusz Dudek \\ $2^{\text {nd }}$ Department of Cardiology, Jagiellonian University Medical College, Krakow, Poland
}

Postep Kardiol Inter 2015; 11, 2 (40): 150-151 DOI: $10.5114 /$ pwki.2015.52290

An 87-year-old female patient was admitted to the emergency unit with the diagnosis of non-ST-elevation myocardial infarction (MI). She complained of dyspnea and easy fatigue for 2 days. On admission she was without chest pain and hemodynamically stable (RR 105/ $65 \mathrm{~mm} \mathrm{Hg}$ ). The electrocardiogram revealed ST-segment depression in leads II, III, aVF and V4-V6 and ST-segment elevation in leads $\mathrm{V} V \mathrm{R}$ and $\mathrm{V} 1-\mathrm{V} 2$. In the angiography performed from the right radial artery, acute left main coronary artery (LMCA) occlusion was found (Figures $1 \mathrm{~A}, \mathrm{~B}$ ). During catheterization the patient developed cardiogenic shock with arterial pressure drop to $60 / 20 \mathrm{~mm} \mathrm{Hg}$. Immediate percutaneous coronary intervention $(\mathrm{PCI})$ of LMCA was started. Due to severe spasm of the right radial artery, the introduction of a regular guiding catheter was impossible. Then sheathless 3.5JL catheter was effectively positioned in the ostium of the LMCA. After passing the occlusion with the BMW Universal wire (Abbott Vascular, USA), aspiration thrombectomy was unsuccessfully attempted. Predilatation with a small balloon $(2.0 \times 15 \mathrm{~mm}$; Sprinter Legend, Medtronic, USA) was performed and complete flow through the LMCA was restored. Two zotarolimus-eluting coronary stents $(3.0 \times 26 \mathrm{~mm}$ and $2.5 \times 18 \mathrm{~mm}$; Resolute Integrity, Medtronic, USA) were implanted from the LMCA ostium to the proximal left anterior descending artery (Figure $1 \mathrm{C}$ ). After implantation of the stents her systolic blood pressure stabilized at about $110 \mathrm{~mm} \mathrm{Hg}$ without pharmacological support. She was transferred to the cardiac intensive care unit. After 30 min she developed severe pulmonary edema which was successfully treated with the standard pharmacological regimen. There were no further complications during the hospitalization. She was discharged home on the sixth day. Left ventricular ejection fraction at discharge was $45 \%$. There were no cardiovascular events during 4-month follow-up.

Acute MI (AMI) due to LMCA occlusion is a rare situation but very often associated with severe clinical consequences (cardiogenic shock, life-threatening arrhythmias, sudden cardiac death) [1]. There have been no randomized trials comparing revascularization strategies ( $\mathrm{PCl}$ vs. coronary artery bypass grafting) in this group of patients. However, according to certain assumptions (less invasive procedure, fast access, better acute results) PCI may be superior to cardiac surgery in this clinical scenario. Recent data show effectiveness of PCI of the LMCA in AMI even in centers without on-site cardiac surgical backup [2]. However, due to high probability of cardiogenic shock (from $16 \%$ to $69 \%$ ) among patients with $\mathrm{AMI}$ due to an occlusion of the LMCA, hemodynamic support with an intra-aortic balloon pump or left ventricle assist device during the procedure is frequently required (from $23 \%$ to $89 \%)[3,4]$. The transradial approach for unprotected LMCA disease is a reasonable option also in patients with $\mathrm{AMI}$, as the rate of procedural complications is similar to that reported for the femoral access [5]. Ostial/midshaft LMCA lesions are relatively straightforward to treat. Distal bifurcation lesions could be more tricky but treatable through the transradial approach. The transradial approach is also useful in patients with hemodynamic instability (pulmonary edema) after $\mathrm{PCl}$, when a patient can be safely placed in a sitting position and effectively treated with pharmacotherapy only.

\section{Conflict of interest}

The authors declare no conflict of interest.

\section{Corresponding author:}

Michat Chyrchel MD, PhD, $2^{\text {nd }}$ Department of Cardiology, Jagiellonian University Medical College, 17 Kopernika St, 31-501 Krakow, Poland, phone: +48 1242471 81, e-mail: mchyrchel@gmail.com

Received: 26.03.2015, accepted: 19.04.2015. 

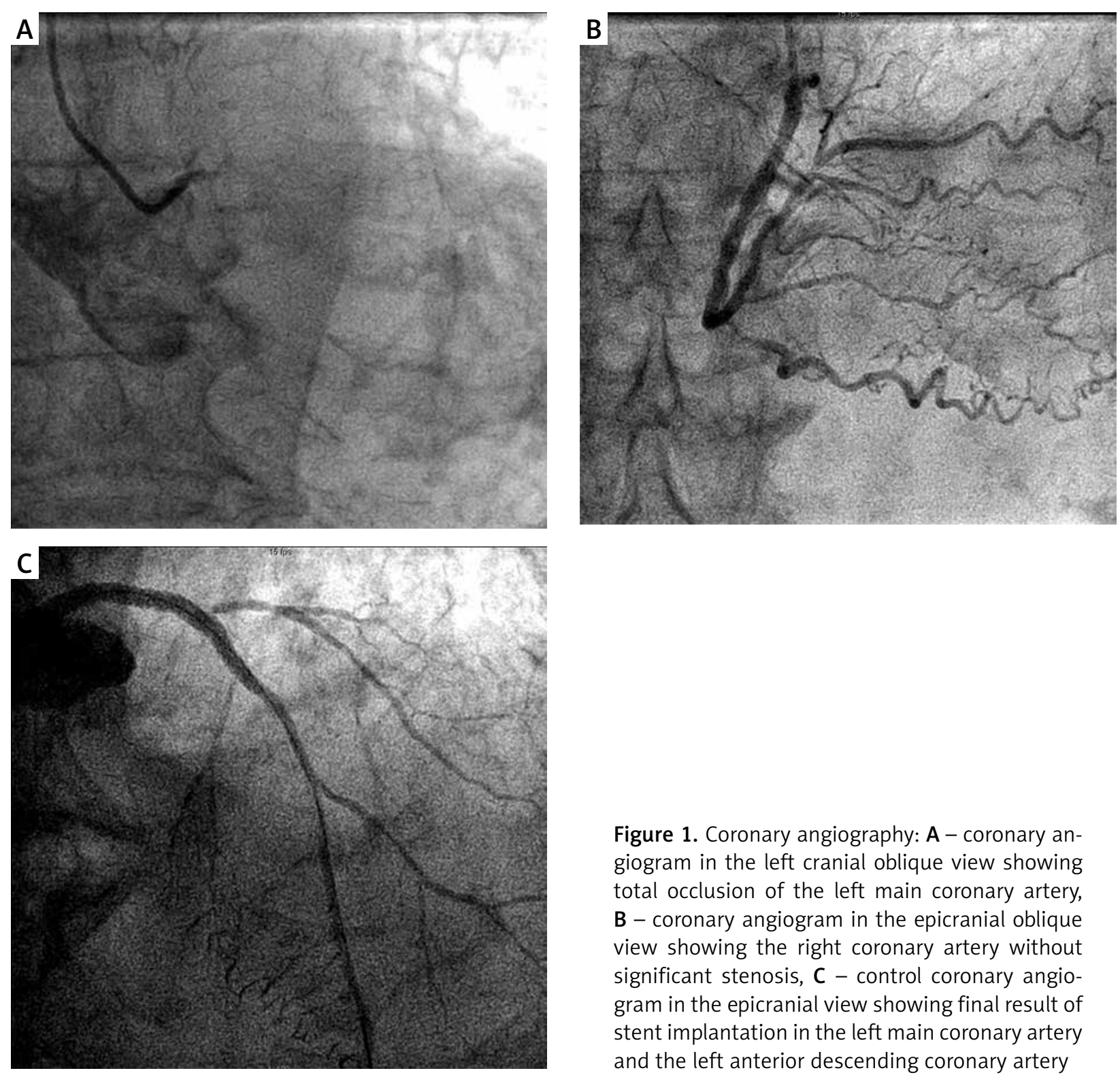

Figure 1. Coronary angiography: A - coronary angiogram in the left cranial oblique view showing total occlusion of the left main coronary artery, B - coronary angiogram in the epicranial oblique view showing the right coronary artery without significant stenosis, C - control coronary angiogram in the epicranial view showing final result of stent implantation in the left main coronary artery and the left anterior descending coronary artery

\section{References}

1. Pedrazzini GB, Radovanovic D, Vassali G, et al. Primary percutaneous coronary intervention for unprotected left main disease in patients with acute ST-segment elevation myocardial infarction the AMIS (Acute Myocardial Infarction in Switzerland) plus registry experience. JACC Cardiovasc Interv 2011; 4: 627-33.

2. Pappalardo A, Mamas MA, Imola F, et al. Percutaneous coronary intervention of unprotected left main coronary artery disease as culprit lesion in patients with acute myocardial infarction. JACC Cardiovasc Interv 2011; 4: 618-26.

3. Lee MS, Dahodwala MQ. Percutaneous coronary intervention for acute myocardial infarction due to unprotected left main coronary artery occlusion: Status Update 2014. Catheter Cardiovasc Interv 2015; 85: 416-20.

4. Pyka L, Pres D, Przybylski R, et al. Mechanical circulatory support in cardiogenic shock - what every interventional cardiologist should know. Postep Kardiol Inter 2014; 10: 195-200.

5. Yang YJ, Kandzari DE, Gao Z, et al. Transradial versus transfemoral method of percutaneous coronary revascularization for unprotected left main coronary artery disease: comparison of procedural and late-term outcomes. JACC Cardiovasc Interv 2010; 3: 1035-42. 